Research Journal of Applied Sciences, Engineering and Technology 5(3): 889-897, 2013

DOI:10.19026/rjaset.5.5036

ISSN: 2040-7459; E-ISSN: 2040-7467

(C) 2013 Maxwell Scientific Publication Corp.

Submitted: June 19, $2012 \quad$ Accepted: July 04, $2012 \quad$ Published: January 21, 2013

Research Article

\title{
The Relationship between the Performance of Industrial Clusters and Renovation of Small Industries
}

\author{
${ }^{1}$ Karim Esgandari, ${ }^{2}$ Hamed Tirandazheravi, ${ }^{2}$ Jafar Beikzad and ${ }^{3}$ Majid Khalili \\ ${ }^{1}$ Department of State Management (financial attitude), Young Researches Club, \\ ${ }^{2}$ Department of Management, Bonab Branch, Islamic Azad University, Bonab, Iran \\ ${ }^{3}$ Department of Industrial Management, Tabriz Branch, Islamic Azad University, Tabriz, Iran
}

\begin{abstract}
The purpose of the present study is investigating the relationship between the performance of industrial clusters and renovation of small industries in East Azerbaijan, Iran. In this study, the relationship between the performance of the industrial clusters and its dimensions including the supporting institutions, communicative sectors and production-business sectors has been investigated using the renovation indices of small industries. The participants of the study include all 243 industrial and production units in auto-parts manufacturing cluster of the province. Due to the limited number of subjects, census-taking was used. The data collection instrument for the study was questionnaire. The validity of questionnaire was confirmed through face value of content and its reliability was confirmed using Cronbach's Alpha, with 0.838 for the questions on industrial clusters' performance and 0.726 for the questions on small industries development. To test the research hypotheses, Pearson and Friedman tests were used. The results indicate that there is a relationship between the performance of industrial clusters and its dimensions, with renovation of small industries in the province.
\end{abstract}

Keywords: Auto-parts cluster, industrial clusters, renovation of small industries, small industries

\section{INTRODUCTION}

In recent decades, many content and qualitative changes in global marketing have taken place and movement toward the globalization of markets has just begun. Along this process, the era of productioncenteredness has just reached its end and customercenteredness is still rising. Industrial producers with the aim of ensuring the optimal use of available facilities and preventing the waste of valuable resources have resorted to some measures resulting in the changes in industrial structure. The main feature of the structural change is the promotion of small industries. In recent years, more attention has been paid to downsizing and the development of SMEs (Small and Medium Enterprises) has sharply increased. These enterprises have many advantages as compared with large industries such as the value added, innovation, creation of job opportunities and more flexibility. Therefore, paying more attention to this aspect of economy is necessary. On the other hand, the small size of enterprises and the little available recourses have created some limitations for these enterprises, namely financial, development and research, marketing restrictions and so on etc. Small industries represent a significant proportion of each country's economy. This sector provides the necessary basis needed for economic development. These industries provide job opportunities in each country and strengthen the foundations of economy, eventually causing an increase in national revenue of that country. Because modern small industries can play an important role in strengthening and diversifying the industrial structure and accelerating industrialization, almost all developing countries and governments seek to promote them in their developing programs and policies. In most of the countries, a significant of economic activities is done by SMEs. These industries can locate their own specific problems in entering the arena of global competition. Governments always try to support these companies logically using different strategies in order to enhance their competitiveness in a way that they can compete in competitive world markets. Developments and changes in competitive ability over the time have turned into the main research topics on industrial clusters one of the basic strategies in organizing SMEs is integrating and organizing these enterprises in industrial clusters.

Concentration, of a number of SMEs in one geographical area can create advantages for withincluster enterprises. In other words, by integrating the companies which operate in similar or related fields, these Companies may enjoy advantages such as savings resulting from scale and diversity, knowledge and

Corresponding Author: Karim Esgandari, Department of State Management (financial attitude), Young Researches Club, Bonab Branch, Islamic Azad University, Bonab, Iran

This work is licensed under a Creative Commons Attribution 4.0 International License (URL: http://creativecommons.org/licenses/by/4.0/). 
technology transfer, increasing competitiveness resulting from collective efficiency.

The importance of industrial development in developing countries has led many countries to considering the formation and strengthening of cluster SMEs in industrial areas as a regional industrial development strategy. The countries try to exploit small industries as an employment strategy which, meanwhile, is able to exploit the competitive ability of companies and increase their exports. In the past 2 decades, in order to accelerate economic growth and creation of job opportunities, the study of industrial clusters has gained a special importance (Rabeloty, 2004). One of the methods for industrial development which, in recent years, has proved to be appealing for developing and developed countries is their inclination toward downsizing the industries, reliance on development and expansion of theses industries. With the dramatic changes in the world particularly the changes in different industries, small industrials are increasingly growing and flourishing. Small industries create nearly $30 \%$ of industrial output, but in terms of the creation of job opportunities, they have an important contribution. Since supporting dispersed and small industrial units is both hard and costly for the governments, encouraging and pursuing these units to aggregate in clusters and industrial networks can be considered as a successfully experienced strategy by policy makers and executives in many countries (Schmitz and Nadavi, 2002).

The main purpose of this research is investigating the relationship between the performance of the industrial clusters and its dimensions including supporting institutions, communication sectors and production-business sectors with renovation of small industries in the society under study.

\section{LITERATURE REVIEW}

In recent years, fundamental and profound changes have occurred in approaches to economic development. Meanwhile, the development and expansion of clusters has become an efficient strategy for gaining competitive advantage and entrepreneurial growth in the global economy.

Industrial cluster: Cluster is the geographic concentration of institutions and their respective companies in a particular field (Porter, 1998). A cluster is a set of companies, organizations, associations and active professional organizations in an industrial field which through an interconnected relationship of networks is able to synergize the capabilities of that set. Generally, industrial cluster forms at an urban or regional geographical scale and carries several specific properties. Cluster is a set of companies which are centered in a geographical area or zone and faces many common threats and opportunities. These companies produce and distribute a set of related or complementary products. Such a focus creates the related businesses and leads to the emergence of specialized services in technical, management and financial fields (Iran-Nejad and Razavi, 2002). The formation and expansion of clusters is done through the following ways:

- Locating and replacement of the whole or part of institutional activities in a cluster in order to use the external effects of clusters.

- Integrating the new institutions with horizontal or vertical cooperation structures (Maskell, 2001).

Industrial cluster is a homogenous set of industries which is formed with economic objectives in geographical regions due to the presence of special advantages or socially consolidated capitals such as technology and skill (Majidi, 2002). Cluster attracts a lot of dealers to buy the products and sell them in distant markets. Moreover, since offering certain services and facilities to companies individually is costly, clustered companies facilitate services offered by governments, large corporations, universities and other organizations that support development (Tambunan, 2005). Industrial cluster is a model for organizing SMEs so that, besides having its own advantages such as product diversity and flexibility, they would also enjoy the advantages of mass production. Today industrial cluster plays a significant and central role in the economic and industrial policies of many developed and developing countries (Pike, 2004).

Industrial cluster is a set of companies and organizations located in a specific geographical area that forms an inter-group communication of products and services through internal relationships (Ketels, 2004). The main reason for the attention of policymaking circles to industrial clusters is their potential for the creation of jobs. Moreover, the success of SME clusters in the global market and their competitive capacity has been appealing for policymakers and politicians.

According to the main findings, the experience of strengthening the clusters and networks, the supporting aids and policies can be effective as long as they possess the following features:

- Being customer oriented: If the companies are aided in better, fast and comprehensive identification of their customers' needs, they can definitely solve their problems more efficiently and compete more seriously. 
- Being collective: Supporting the companies should be in the form of organized companies, this form of support not only minimizes transaction costs but it also encourages cooperation and mutual learning.

- Being cumulative: The creation of new capacities in order to upgrade the performance so that they would not require further governmental support (Schmitz and Nadvai, 1999, 112). Increasing the knowledge of business owners about the benefits of the creation of networks is one of the first measures adopted by experts and policy-makers. Identifying problems andways of eradicating them establishes a foundation for creating new networks and local cooperation (Altenburg and Stamer, 1999). One of the issues addressed in the long run, is upgrading and updating the people involved in the development of industrial clusters at national level.

Therefore, besides creating a dynamic communication with international institutions and centers, on the one hand, it provides the possibility of individuals' attendance at training courses and, on the other hand, it provides opportunity to attend seminars and conferences in order to transfer the experiences and gain knowledge (Unido, 2004).

The performance of industrial clusters is:

- Supporting institutions: These institutions have supporting and logistic roles and they provide conditions to access programs by facilitating the provision of technical services for the member enterprises of the clusters (Delangizan, 2006)

- Communicative sectors: Theses sectors organize and facilitate the relations among the enterprises (Delangizan, 2006)

- Production business sectors: As a sector that presents manufacturing services and provides required goods for cluster units (Din Mohammadi et al., 2005)

Renovation of small industries: The development of small and medium industries in economy has increased their impact on economic indices in recent years. These industries, with their significant amount of exports, play an effective role in the economic development of their own countries. Thus, small and medium industries are regarded as appropriate bases for creating capable and competitive industries and in most countries the development of an appropriate policy for these industries has been emphasized (Acs, 2004). Governments have no specific and separate policy for the development of small institutions as separate economic sectors, but development in this important sector has been considered within the overall objectives of industrial development (UNO, 1987). There are different models of industrial growth in advanced economies. Some of these differences are due to the involvement of the countries at different stages of economic cycle. Some others are related to specific systems and their historical, political and social conditions. There are consistent ideas on the urgent need of the countries which are not sufficiently developed; this suggests that the vast range of opportunities be available to local and conversion industries, as done in practice (Gharacheh, 1998).

Small industry means any kind of manufacturing activity which is done in relatively small enterprises (Moussaovi, 2004). There are different criteria for defining this kind of industries. In some countries just 1 and in some others a combination of them may be used to define small and medium industries. Some of these criteria are the number of employees, the amount of capital, the volume of assets, the volume of total sales and production capacity. But the most common definition for small and medium industries is based on the number of staff (IBSAR, 2006). In defining small and medium industries, the following points are often considered:

- In defining industries, due to the common characteristics of small and medium industries, in most cases these 2 groups come together (Nilli, 2003).

- SMEs include manufacturing industries and commercial services institutions. Apart from the criterion which is used to define small and medium industries these kinds of industries refer to industries which are managed independently and companies which operate as a branch of a large company are not included in this definition (Karami, 2008).

Small industries are industries in which 4-50 employees are working (Mo'laee, 2004)

According to the definition offered by the European Commission, small and medium industries refer to all industries with Fewer than 250 employees with less than 40 million Euros turnover or less than 27 million Euros financial balance (Karami, 2008).

Small industries contribute to the global economy at least four ways:

- Creation of job opportunities: Small industries expedite the growth of entrepreneurial spirit and act as change agents in modern economies accelerating the economic growth.

- Innovation: Small industries have an important role in the process of technological change and are significant sources of innovative activities.

- Dynamicity of the industry: small industries have an important role in the transformation process of industry. 
- Creating job opportunities: In recent years, small industries have significantly contributed to the creation of new jobs (Acs and Audretsch, 1991).

According to Delangizan's theory, an industrial cluster includes a collection of commercial and noncommercial enterprises located in a geographical location of an economic zone. In this industrial cluster, to produce one or more similar or related final products for foreign economic efficiency, industrial units establish vertical and horizontal connections with each other and besides competing with each other in many cases they have collective cooperation and common measures as well. Inter-firm relationship reduces the costs and facilitates access to institutions, production technology and know-how, sales markets and meeting customer needs (Delangizan, 2006). Institutions and service providing agencies also create the possibility to offer technical services to cluster member firms, provide their access conditions to public and professional educations at different levels, manpower training and implementation of skill harmonization and standardization programs, development of production programs and technical qualitative planning, successful implementation of programs and equal quality management at different levels, firm commitments to customers, firm's facilities in return for the legal services of writing, execution and pleading of economic conventions and the successful execution of research and development programs. Communication intermediary departments of the firms play their role in the cluster through the creation of a suitable reserve of labor at different skill levels, a reservoir of technical service expertise in machinery repair/maintenance sector and the storage of social capitals related to the joint group actions of the firms as well as their independent activities within clusters. Also according to the theory of Entire, industrial clusters are a group of firms and financial and non-financial institutions, which are in contact with each other horizontally and vertically and cooperate and compete with each other in various fields. In fact, the key element for the group members is their competitive performance. What makes these clusters related to each other is the mutual relationship between member firms as buyers and suppliers of their needs. Such as joint purchases, the use of common distribution networks, the use of common usable technologies, shared distribution channels, technological communications, joint researches, staff training background, joint training of managers, joint market studies, consultation the formation of joint human capital and using the common bases for labor market. Firms depend on each other for their commercial and manufacturing products. Competition among the firms is important. It will lead to a permanent pressure on the firms to constantly use superior technologies and search for new opportunities. Moreover, in this situation there are always opportunities for some competitors to cooperate with each other in order to solve the common and similar problems. They can even try to solve their problems by cooperating with each other (Delangizan, 2006)

The development of small industries is an increase in utilization of institutions along with an increase in economic efficiency and the use of probable unused capacities for increasing the capability of production as well as the reduction in final price. In other words, the development of small industries means the development and growth of industries in terms of having favorable conditions and competitive advantages, in dimensions such as export, the renovation of industry and profits (Zoghi, 2008). The indices for the renovation of small industries are divided into two dimensions, technical and economical:

- The technical indices include:

- Replacement-and changing worn-out machineries with new and modern models

- Production of new products

- Increase income by designing new products

$\circ \quad$ Better shipping and handling of the materials

- Employing at least $13^{\text {rd }}$ of the educated labor force with associate's degrees or higher

- Use knowledge and skills

○ Having correct management

- Enjoying the process of automated engineering design and production lines

- Change in software and hardware technologies of production units

○ Enjoying advanced technology

- Providing after-sale services

- The economical indices include:

- Increasing production capacity by lowering the final prices

- Increasing the speed of capital investment's return

- Increasing the amount of sales

- Diversity of the products

- Exportig the products

- Offering competitive prices in the domestic and foreign markets (Mo'llaee, 2004)

A selection of previous researches on the topic is as follows: Salkow (2007) studied the effects of using management styles on the success of small industries in Canada's textile industry. This study sought to find whether the director focused deeply on organizational production? Or he considers people's satisfaction? Or both objectives are pursued by the manager? Research results have shown that the managers of industrial units 
use different leadership styles in their own organizations and their level of success in running their own industrial units is a function of the style adopted.

Karami (2005) has surveyed the views of senior managers in strategic management process in electronics industry SMEs of England in relation to their internal and external environments. He has offered a dynamic model for the strategic management of small industries. The research results indicate that firms which use strategic management techniques, either formally or informally, have an improved level of success in formulating and implementing business strategies. Also, applying the strategic management process in small industries fundamentally helps to solve organizational problems and reduces organizational conflicts. Meanwhile, creating a search system as a part of strategic management process is essential for formulating and planning the business strategy that promotes profitability and increases the rate of industrial growth in development and adaptation to unexpected environmental changes in the turbulent markets.

Sharafinejad (2007) evaluated and prioritizing the factors affecting the expansion of the exports of small and medium confectionary and chocolate industries in Tehran (Iran) The results showed that the variables of product packaging, product diversification, cost, distribution, public relations, human resources, domestic demand conditions, marketing strategies, identification and evaluation of international marketing environment and attention to the market differences among statistical samples were at average level. Also, the amount of advertising variables, pre-sales, scientific and research facilities, financial resources, the role of government, absence of unexpected volatility, marketing research, supporting and related industries and enjoying infrastructures within statistical community were lower than average. Meanwhile, the variables of quality, products, raw materials, enjoying technology, intensity of domestic competition, strategic management approach and management knowledge were above average. The results also indicate that the priority orders of these factors from the highest to the lowest are as follows: The quality of products, strategic management approach, the intensity of domestic competition, the potentials of management knowledge, raw materials, enjoying technology, sale promotion, marketing research, absence of unexpected volatility, advertising, enjoying infrastructures, supporting and related industries, financial resources, the role of government and scientific and research facilities.

Shahmoradi (2006) in a research investigated the factors involved in the industrial cluster formation in small industries, a case study of furniture making business in Malayer, Iran.

The main purpose of it was to study the design and to identify the main model of industrial cluster structure of furniture making business in Malayer. The model investigated the possibility of whether these mechanisms were largely able to create a geographical focus or not? The results of the study indicated that human resources capital, joint research and development projects, the local synergy of public opinions and risky asset increase the geographical focus. Thus, causing the emergence or strengthening of the industrial clusters.

Kazemi (2002) designed and defined a strategic planning model for small industries (parts making industry) and did a comparative study of it against larger industries in part making industry. He identified the difference between strategic planning in small and large industries.

The theoretical framework of the study: In this study, in order to find the relationship between the performance of industry clusters and renovation of small industries in the population under study, both Delangizan's and Enrate theories were used to show the performance of industrial clusters (Fig.1), which include:

- The performance of supporting institutions including securing training needs of the staff, teaching and training of the managers, providing the facilities for development, increasing supervision and legality, providing services by the association.

- The performance of communication sectors including: using common technologies; conducting joint studies, conducting joint researches, offering joint laboratory services, joint purchases by the networks, selling products by joint distribution networks, supplying qualified and specialized manpower, using the homogenous strategies, joint maintenance and repair, supplying technological communications.

- The Performance of production-business sectors including: providing necessary intermediate goods, providing necessary capital goods, offering production services, offering technical and professional advices and signing research and development contracts.

Also, the evaluation indices of renovation in small industrial units can be divided into technical and economical indices, the most important features of which are Vepa (1994): 


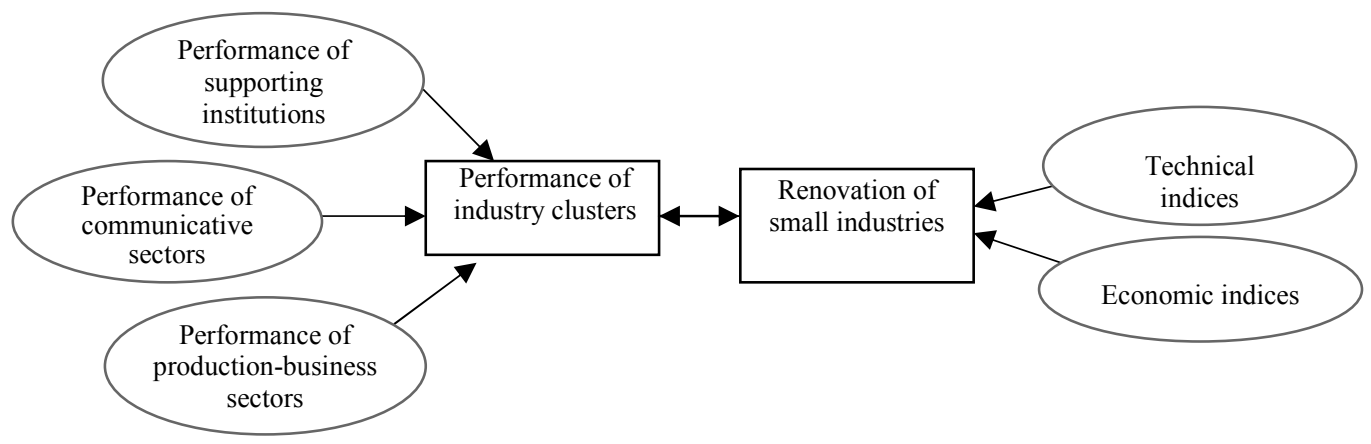

Fig. 1: the theoretical framework of research

- The technical indices include:

- Replacement and changing of worn-out machineries and equipment with new and modern models

- Better shipping and handling of materials

- Control the exact inventory of company

- Having correct management

- Having at least one third of the educated labor force with associate's degrees or higher

- Enjoying designing and producing processes as well as a mechanized line of engineering production

$\circ \quad$ Changing the technology of hardware and software of production units at least once over the past five years

- Enjoying advanced technology of marketing for introducing and selling products

- Provideing after-sale services

- Important economic indices including:

- Increase in sale rate

- Increasing production capacity with lowering the final price

- Increase in the speed of investments return

- Exporting the products

- Diversity in products

- Enjoying competitive prices in domestic and foreign markets

- High productivity of production agents

Research hypotheses: Hypotheses corresponding with research objectives include:

- There is a correlation between the performance of industrial clusters and renovation of small industries.

- There is a correlation between performance of industrial clusters' supporting institutions and renovation of small industries.
- There is a correlation between the performance of communicative sectors of industrial clusters and renovation of small industries.

- There is a correlation between the performance of production-business sectors of industrial clusters and renovation of small industries.

- There is a difference between the correlations of the dimensions of the performance of industrial clusters and the renovation of small industries.

\section{METHODOLOGY}

The present study is survey-based in methodology, analytical in type and applied in purpose. The statistical population of the study includes 232 managers of small industrial units operating in auto parts cluster in the community under study. Due to the limited nature of statistical population, the whole population is considered as the statistical sample. The instrument for gathering the data is researcher-made questionnaire. Questionnaire scale is 5-option liker scale. To determine the validity of data gathering instrument, face content validity was used. Cronbach's alpha for estimating the reliability of the questionnaire was used. The values for independent and dependent variable were 0.760 and 0.741 respectively that indicate adequate reliability.

Method of statistical data analysis: In order to analyze the data from the questionnaires, descriptive and inferential statistical were used. Frequency distribution tables and responses percentages were used to statistically describe the data. To test the hypotheses and generalize the results Pearson and Friedman tests were used. SPSS software was used for the calculations

Statistical description of questions in questionnaire and research variables: According to the data given in Table 1, we observe that $100 \%$ of statistical populations are men. Also, based on information in 
Res. J. Appl. Sci. Eng. Technol., 5(3): 889-897, 2013

Table 1: Frequency distribution and percentage of statistical sample responses to question (gender)

\begin{tabular}{|c|c|c|c|c|c|c|c|c|c|c|c|c|}
\hline \multirow[b]{2}{*}{ Gender } & \multicolumn{4}{|c|}{ Male } & \multicolumn{5}{|c|}{ Female } & \multicolumn{3}{|c|}{ Total } \\
\hline & \multicolumn{2}{|c|}{ Frequency } & \multicolumn{2}{|l|}{ (\%) } & \multicolumn{2}{|c|}{ Frequency } & \multicolumn{2}{|c|}{$(\%)$} & \multicolumn{2}{|c|}{ Frequency } & \multicolumn{2}{|c|}{$(\%)$} \\
\hline Response quantity & \multicolumn{2}{|c|}{223} & \multicolumn{2}{|l|}{100} & \multicolumn{2}{|c|}{0} & \multicolumn{2}{|c|}{0} & \multicolumn{2}{|c|}{223} & \multicolumn{2}{|c|}{100} \\
\hline & \multicolumn{2}{|c|}{ Under 25} & \multicolumn{2}{|c|}{$25-35$} & \multicolumn{2}{|c|}{$36-45$} & \multicolumn{2}{|c|}{$46-55$} & \multicolumn{2}{|c|}{ More than 55} & \multicolumn{2}{|c|}{ Total } \\
\hline Age & $\mathrm{F}$ & $\mathrm{P}$ & $\mathrm{F}$ & $\mathrm{P}$ & $\mathrm{F}$ & $\mathrm{P}$ & $\mathrm{F}$ & $\mathrm{P}$ & $\mathrm{F}$ & $\mathrm{P}$ & $\mathrm{F}$ & $\mathrm{P}$ \\
\hline \multirow{2}{*}{ Response quantity } & 0 & 0 & 118 & 50.9 & 80 & 34.9 & 31 & 12.9 & 3 & 1.3 & 232 & 100 \\
\hline & \multicolumn{2}{|c|}{ Diploma } & \multicolumn{2}{|c|}{ Associate } & \multicolumn{2}{|c|}{ Bachelor } & \multicolumn{2}{|c|}{ Master } & \multicolumn{2}{|c|}{$\mathrm{PhD}$} & \multicolumn{2}{|c|}{ Total } \\
\hline Educational degree & $\mathrm{F}$ & $\mathrm{P}$ & $\mathrm{F}$ & $\mathrm{P}$ & $\mathrm{F}$ & $\mathrm{P}$ & $\mathrm{F}$ & $\mathrm{P}$ & $\mathrm{F}$ & $\mathrm{P}$ & $\mathrm{F}$ & $\mathrm{P}$ \\
\hline \multirow[t]{2}{*}{ Response quantity } & 0 & 0 & 65 & 23 & 148 & 63.8 & 19 & 8.2 & 0 & 0 & 232 & 100 \\
\hline & \multicolumn{2}{|c|}{ Under 5} & \multicolumn{2}{|l|}{$5-10$} & \multicolumn{2}{|c|}{$11-15$} & \multicolumn{2}{|c|}{$16-20$} & \multicolumn{2}{|c|}{ More than } & \multicolumn{2}{|c|}{ Total } \\
\hline Management records & $\mathrm{F}$ & $\mathrm{P}$ & $\mathrm{F}$ & $\mathrm{P}$ & $\mathrm{F}$ & $\mathrm{P}$ & $\mathrm{F}$ & $\mathrm{P}$ & $\mathrm{F}$ & $\mathrm{P}$ & $\mathrm{F}$ & $\mathrm{P}$ \\
\hline Response quantity & 35 & 15.1 & 83 & 35.8 & 78 & 33.6 & 29 & 12.5 & 7 & 3 & 232 & 100 \\
\hline
\end{tabular}

Table 3: Descriptive statistics for the variables of the study

\begin{tabular}{|c|c|c|c|c|c|}
\hline & Dimensions of the perfe & rmance of industrial clust & & & \\
\hline & Supporting institutions & Communicative sectors & $\begin{array}{l}\text { Production-business } \\
\text { sectors }\end{array}$ & $\begin{array}{l}\text { Performance of } \\
\text { industrial clusters }\end{array}$ & $\begin{array}{l}\text { Renovation of } \\
\text { small industries }\end{array}$ \\
\hline Total & 232 & 232 & 232 & 232 & 232 \\
\hline Missing & 0 & 0 & 0 & 0 & 0 \\
\hline Mean & 9.500 & 20.170 & 9.9700 & 39.650 & 44.190 \\
\hline Median & 9 & 19 & 9 & 37 & 44 \\
\hline Mode & 9 & 17 & 9 & 36 & 44 \\
\hline Std. deviation & 2.401 & 5.2060 & 3.2460 & 8.2770 & 6.6120 \\
\hline Variance & 5.766 & 27.101 & 10.536 & 68.537 & 43.724 \\
\hline Range & 16 & 31 & 17 & 54 & 34 \\
\hline Minimum & 5 & 12 & 5 & 25 & 31 \\
\hline Maximum & 21 & 43 & 22 & 79 & 65 \\
\hline
\end{tabular}

Table 4: Pearson test to investigate the correlation of industrial clusters 'performance and renovation of small industries

\begin{tabular}{|c|c|c|c|c|}
\hline Variable & $\mathrm{N}$ & Sig (2-tailed) & $\begin{array}{l}\text { Renovation of small } \\
\text { industries }\end{array}$ & $\begin{array}{l}\text { Coefficient of } \\
\text { determination }\end{array}$ \\
\hline Performance of industrial clusters & 232 & 0.000 & 0.273 & $(0.273)^{2} \times 100=7.45$ \\
\hline $\begin{array}{l}\text { Performance of } \\
\text { supporting institutions }\end{array}$ & 232 & 0.000 & 0.170 & $(0.170)^{2} \times 100=2.89$ \\
\hline Performance of communicative sectors & 232 & 0.000 & 0.236 & $(0.236)^{2} \times 100=5.56$ \\
\hline $\begin{array}{l}\text { Performance of } \\
\text { production-business sectors }\end{array}$ & 232 & 0.000 & 0.192 & $(0.192)^{2} \times 100=3.68$ \\
\hline
\end{tabular}

Table 2, 50.9\% of the people under study were between $25-35$ years, $34.9 \% 36-45$ years, $12.9 \%$ between $46-50$, $1.3 \%$ were over 55 years. The statistical sample consisted of $28 \%$ of subjects with an associate's degree, $63.8 \%$ had BA and $8.2 \%$ had a master's degree. Also $15.1 \%$ of the statistical sample had less than 5 years management experience, 35.8 had $5-10$ years, $33.6 \%$ had $11-15$ years, $12.5 \%$ had $16-20$ years and $3 \%$ had 5-10 years of working experience. Also, Statistical description of research variables is according to Table 1.

Based on information given in Table 3 the average performance of independent variable in industrial clusters is equal to 39.65. The average performance dimensions in industrial clusters' variables including supporting institutions, communicative divisions and business and manufacturing sectors are 9.50, 20.17 and 9.97, respectively. And the average of dependent variable in the renovation of small industries is 44.19.

Inferential analysis of statistical data (the statistical test of research hypotheses): After defining each research hypothesis statistically, the results of testing them as given in Table 5 and 6 were obtained. As evident in Table 4, the level of significance in 2 tailed Pearson test for all hypotheses was $p=0.000$ and this level was less than the minimum level of significance (0.05). Thus in all hypotheses there is a meaningful correlation between the 2 variables, so $\mathrm{H}_{0}$ is rejected. Also, as can be seen in Table 5. Since the significance level of Friedman test is less than the minimum level of significance (0.05), $\mathrm{H}_{0} \quad$ is rejected. 
Res. J. Appl. Sci. Eng. Technol., 5(3): 889-897, 2013

Table 5: Friedman test to investigate the performance of industrial clusters and renovation of small industries

\begin{tabular}{llll}
\hline A: test statistics & & B: ranking & Mean rank \\
\hline $\mathrm{N}$ & 232 & Performance dimensions of industrial clusters & \\
Chi-square & 354.664 & Performance of supporting institutions & 1.49 \\
Df & 2 & Performance of communicative sectors & 2.98 \\
Asymp. Sig & 0.0000 & Performance of production-business sectors & 1.53 \\
\hline
\end{tabular}

Therefore, it can be concluded that there is a meaningful difference between the correlation of industrial clusters' performance dimensions and renovation of small industries and this can be classified as follows:

- Performance of communicative sectors

- Performance of production-trade sectors

- Performance of supporting institutions

\section{CONCLUSION}

The results corresponding to the research hypotheses based on the information and analysis in Table 4 and 5 include:

- There is a correlation between the performance of industrial clusters and renovation of small industries. The obtained coefficient of determination shows that industrial clusters' performance indicates $7.45 \%$ of variance of small industries' renovation. It means $7.45 \%$ of changes in the renovation of small industries depend on the performance of industrial clusters.

- There is correlation between the performance of industrial clusters' supporting institutions and renovation of small industries. The obtained coefficient of determination shows that supporting institutions' performance indicates $2.89 \%$ of variance of small industries' renovation. It means $2.89 \%$ of changes in the renovation of small industries depend on the performance of supporting institutions.

- There is correlation between the performance of industrial clusters' communicative sectors and renovation of small industries. The obtained coefficient of determination shows that communicative sectors' performance indicates $5.56 \%$ of variance of small industries' renovation. It means $5.56 \%$ of changes in the renovation of small industries depend on the performance of communicative sectors.

- There is correlation between the performance of industrial clusters' production-business sector and renovation of small industries. The obtained coefficient of determination shows that, production-business sector' performance indicates $5.56 \%$ of variance of small industries' renovation. It means $5.56 \%$ of changes in the renovation of small industries depend on the performance of production-trade sectors.

- There is a difference between the correlations of industrial clusters' performance dimensions and renovation of small industries. The correlations of industrial clusters' performance dimensions and renovation of small industries can be ranked as follows:

- Performance of communicative sectors

- Performance of production-trade sectors

○ Performance of supporting institutions

\section{RECOMMENDATIONS}

According to the results of study, in order to renovate the small industries and improve the performance of industrial clusters, it is suggested that:

- Increasing the protection of supporting institutions: It is recommended to achieve proper policies in order to better meet the educational needs of staff units, proper education and training of managers, providing better facilities for the development of units, more surveillance and legality on units and providing more services to units by the association, to improve the performance of supporting institutions in order to develop the small industries at a higher level.

- Strengthening the communicative sectors: It is recommended that an order be adopted so that the units would cooperate more while competing against each other. Also they should establish more interconnections among them such as: strong technological communications, participating in joint exhibitions, joint purchases through available networks in units, doing joint studies and researches within units, supplying qualified and specialized manpower in units, using similar strategies within units, etc.

- Strengthening production-business sectors: It is recommended that these sections become selfsufficient in providing the needed goods such as intermediate and capital goods. Moreover, by providing better production services and offering technical and professional advice for the units can fulfill the needs of units and improve their performance in order to solve problems and sign research and development contracts. 


\section{REFERENCES}

Acs, Z.J. and D.B. Audretsch, 1991. Innovation and Technological Change: An International Comparison. Ann Arbor: University of Michigan Press, USA.

Acs, Z.J., 2004. Small Industry Role in Modern Economic. Translated by Jahangir Majidi, Tehran, 2nd Edn., Saba art Cultural Institute, Tehran.

Altenburg, T and J. Meyer Stamer, 1999. How to promote clusters: Policy experience from Latin America. World Dev., 27: 168.

Delangizan, S., 2006. Survey of industrial cluster place in achieving advantage and export power (textile industry of china cloth), Taavon J., 273: 33-36.

Din Mohammadi, M., 2005. Spatial clustering of industry by major technology and its effect on technology development. Proceeding of the 2nd Iranian Seminar of High Education and Occupation, Tarbiat Modares University, Tehran, pp: 4.

Gharacheh, M., 1998. Small industry management. Job Management Report no. 35, Job and Social Security Institute of Iran, Tehran.

Iran-Nejad, J. and M.R. Razavi, 2002. Industrial Cluster. Neo Publication, Tehran.

Karami, A., 2005. Survey of high manager attitude and strategic management process in small cooperates. Ph.D. Thesis, International Development University, UK.

Karami, A., 2008. Strategic Attitude to Survey of SMEs role and Presenting Development Approach in Eastern Azerbaijan. 1st Edn., Assistance of Ministry Planning, Tehran.

Kazemi, M., 2002. Design and strategic planning model for small industry (Piece making industry) and comparing whit great industry. MA Thesis, Management Faculty of Tehran University, Tehran.

Ketels, C., 2004. Cluster-Based Economic Development: What Have We Learned. Harvard Business School, DTI, London, UK.

Majidi, J., 2002. Industrial Cluster. 1st Edn., Small Industry and Industrial Cities, Tehran.

Maskell, P., 2001. Knowledge creation and diffusion in geographic clusters. Int. J. Innovat. Manag., 5: 213-237.

Mo'llaee, M., 2004. Renovation of small industry in Iran. Tadbir J., 15: 11-17.

Moussaovi, S.M., 2004. Small Industry Pivot of Village Development. 1st Edn., Negin Publication, Tehran.

Nilli, M., 2003. Industrial Development Strategy, Tehran. Sharif Technical University, Tehran.
Pike, F., 2004. Industries Cooperation, Industrial Cluster, Stable Development. Translated by: Bahram Shadabi and Jahangir Majidi, 1st Edn., Hezaran Publication, Tehran.

Porter, M.E., 1998. Clusters and the new economic of competition. Harv. Bus. Rev., pp: 78.

Rabeloty, R., 2004. Industrial Cluster Successful Pattern of Internal Development. Translated By: A. Mehr Puya and J. Majidi, Tehran, 2nd Edn., Rasa art and Cultural Institute, Tehran.

Schmitz, H and K. Nadvai, 1999. Clustering and industrial industrialization: Introduction. World Dev. J., 27: 1503-1514.

Schmitz, H. and K.H. Nadavi, 2002. Industrial Cluster Resent Approach in Industrial Development, Translated By: Abbas Zende Baaf and Abbas Mokhber, 1st Edn., Tarhe No Publication, Tehran.

Shahmoradi, S., 2006. Survey of effective factors in industrial cluster forming in case study industries (malayer furniture making). MA Thesis, Buali University of Hamedan, Hamedan.

Sharafinejad, N., 2007. Survey and grade of effective factors on small and average industry export development (case study: Candy and chocolate industry). MA Thesis, High Education and Research Institute of Management and Planning Organization of Country, Tehran.

Sollkow, C., 2007. Study of management style in small industrial successful. Ph.D. Thesis, Toronto University, Toronto, Canada.

Tambunan, T., 2005. Promoting small and medium enterprises with a clustering approach: A policy experience from Indonesia. J. Small Busin. Manag., 43: 138-154.

Unido, 2004. Summary of result and finding for policy making in small and medium industry. Report of Unido, Publication of small industry organization and corporate of industrial cities of Iran, Tehran.

UNO, 1987. Survey of Small Industry Condition in Asia and Oceania, Rural Industry Committee Central Part of Constrictiveness Jihad. Meraj Publication, Tehran.

Vepa, R., 1994. Renovation of Small Industry and Commercial Units, Asia Efficiency Organization. Translated by Industry Ministry, Industry Ministry of Iran, Tehran.

Zoghi, Y., 2008. Survey of relationship between industrial assembling in industrial cities form and small industry development of eastern Azerbaijan. MA Thesis, Humanities Faculty of Bonab University, Bonab, Iran. 